\title{
PENGENALAN KOSA KATA ARKAIS BAHASA BANJAR DENGAN MEDAN MAKNA BA'AH (BANJIR) DAN EKONOMI DI RRI PRO 4 KALIMANTAN SELATAN
}

\author{
Ida Komalasari $^{1^{*}}$, Norrahmiati ${ }^{2}$, Hasdi Suryadi ${ }^{3}$, \\ ${ }^{1}$ STKIP PGRI Banjarmasin \\ ${ }^{2}$ Universitas Achmad Yani Banjarmasin \\ ${ }^{3}$ Sekolah Tinggi Ilmu Ekonomi (STIE) Pancasetia Banjarmasin \\ *E-mail: idakomalasari56@gmail.com
}

\begin{abstract}
ABSTRAK
Bahasa Banjar merupakan salah satu bahasa daerah milik etnis Banjar di Kalimantan. Dampak perkembangan zaman memberikan efek negatif dalam bahasa Banjar, yaitu mulai bergesernya penggunaan bahasa Banjar oleh penuturnya. Pengabdian ini bertujuan 1) mengenalkan latar belakang adanya bahasa Banjar arkais, 2) mengenalkan pengertian dan contoh bahasa Banjar arkais, 3) mengenalkan medan makna ba'ah 1 melalui puisi Y.S Agus Suseno, 4) mengenalkan medan makna ba'ah 2 melalui puisi Rezky Atmajaya, 5) mengenalkan medan makna ekonomi 1 melalui puisi Y.S Agus Suseno, 6) mengenalkan medan makna ekonomi 2 melalui puisi Rezky Atmajayam, dan 7) Strategi pemertahanan kosa kata arkais Bahasa Banjar melalui siaran pada saluran RRI Pro 4 Banjarmasin. Metode pengabdian ini dalam bentuk Pandiran Baisukan (Bincang Pagi), dan tanya jawab dengan pendengar melalui siaran RRI Pro 4 Banjarmasin. Pengabdian ini dilaksanakan selama 2 bulan sejak Januari 2021 sampai dengan Februari 2021. Tahap pengabdian ini dilaksanakan tujuh kali pertemuan.
\end{abstract}

Kata kunci: $B a^{\prime} a h$, Ekonomi, Etnik Banjar, Kosa Kata Arkais, Medan Makna

\section{INTRODUCTION TO ARKAIS BANJAR VOCABULARY WITH THE FIELD OF MEANING BA'AH (BANJIR) IN RRI PRO 4 KALIMANTAN SELATAN}

\begin{abstract}
Banjar language is one of the regional languages belonging to the Banjar ethnic group in Kalimantan. The impact of the development of the times has a negative effect on the Banjar language, namely the shift in the use of the Banjar language by its speakers. This service aims to 1) introduce the background of the Arkais Banjarese language, 2) introduce the meaning and examples of the Arkais Banjarese language, 3) introduce the meaning field of ba'ah 1 through YS Agus Suseno's poetry, 4) introduce the field of meaning of ba'ah 2 through Rezky's poem Atmajaya, 5) introduces economic meaning field 1 through YS Agus Suseno's poem, 6) introduces economic meaning field 2 through Rezky Atmajayam's poem, and 7) Banjar language archaic vocabulary defense strategy through broadcast on RRI Pro 4 Banjarmasin channel. This service method is in the form of Pandiran Baisukan (Morning Talk), and a question and answer session with listeners through the broadcast of RRI Pro 4 Banjarmasin. This service is carried out for 2 months from January 2021 to February 2021. This service stage is held seven times
\end{abstract}

Keywords: Ba'ah, Economic, Ethnic Banjar, Archaic Vocabulary, Field Of Meaning.

\section{PENDAHULUAN}

Keragaman bahasa daerah di Indonesia yang berjumlah 719 bahasa semakin hari kian berkurang. Berkurangnya bahasa daerah ini dapat berupa punahnya bahasa, berkurangnya pengguna bahasa serta pesatnya perkembangan zaman yang menuntut adanya perubahan terhadap gaya hidup masyarakat dan berimbas pada perubahan Bahasa. Hal ini disebabkan karena Bahasa bersifat dinamis, artinya Bahasa dalam masyarakat dapat berkurang atau bertambah, sesuai dengan kebutuhan masyarakat dalam kegiatan komunikasi. 
Bahasa daerah di Indonesia menduduki bahasa pertama bagi masyarakat, namun dengan adanya tuntutan komunikasi di zaman digital membuat posisi bahasa daerah terpinggirkan. Data Summer Institue of linguistic and Ethnologue (2016) melaporkan bahwa dari 719 bahasa daerah, sejumlah 707 bahasa masih bertahan dan aktif digunakan masyarakat, sementara 12 lainnya telah punah. Selain itu, dari 707 bahasa, sebanyak 701 bahasa daerah yang mendominasi dan sisanya telah bercampur dengan bahasa Indonesia.

Perubahan bahasa terjadi akibat adanya perubahan dan perkembangan penuturnya dalam aspek kehidupan seperti perubahan sosial budaya, perkembangan teknologi informasi bahkan terjadinya kontak bahasa dengan penutur daerah lain. Afria (2017) berpendapat bahwa perubahan bahasa menyebabkan terjadinya perubahan unsur bahasa baik berupa bentuk maupun maknanya. Kosa kata merupakan bagian penting dalam bahasa karena merupakan unsur pembangun dalam kalimat yang menjadi tuturan lisan pengguna bahasa daerah. Secara perlahan, jika sebuah kosa kata jarang digunakan bahkan kemudian tidak digunakan lagi maka kosa kata tersebut digolongkan dalam kosa kata arkais.

Bahasa daerah berperan penting bagi suatu etnis tertentu karena berfungsi sebagai alat komunikasi dalam satu kelompok masyarakat tertentu. Afria (2017) menyatakan bahwa fungsi bahasa dalam masyarakat di suatu daerah yakni, sebagai bahasa lokal dalam suku, bahasa dalam adat istiadat daerah dan sebagai kekayaan adat istiadat suku setempat. Sesuai dengan pendapat tersebut, bahasa juga dapat dikatakan sebagai warisan budaya tak benda karena termasuk tradisi dan ekspresi lisan masyarakat penuturnya.

Bahasa daerah merupakan cerminan aktivitas komunikasi sehari-hari yang berkaitan kehidupan masyarakat seperti sistem keyakinan, sistem sosial, sistem mata pencaharian, sistem teknologi dan kesenian masyarakat setempat. Namun, saat ini sistem kehidupan masyarakat yang telah berubah berpotensi mengurangi kosa kata bahasa daerah, sebab beberapa kosa kata tersebut tidak digunakan dalam kehidupan sehari-hari lagi. Pada akhirnya pemahaman masyarakat penutur terhadap bentuk kata akan berkurang bahkan terncam punah. Oleh sebab itu, sangatlah penting adanya pelestarian dan perlindungan terhadap kosa kata kuno atau arkais.

Chaer dan Leonie (2010) mengungkapkan faktor-faktor perubahan kosa kata suatu bahasa, yaitu :

1) Penyerapan bahasa asing dan bahasa daerah

2) Proses penciptaan kosakata baru

3) Pemberian nama produk atau merek Dagang

4) Pemendekan Kata dan Akronim

5) Penggabungan Kata atau Kata Majemuk

6) Penyingkatan Gabungan Kata

Berdasarkan fakta empiris, penutur bahasa Banjar sebagian besar di kota Banjarmasin tidak menggunakan dan tidak mengetahui kata dan makna kosakata arkais, khususnya dalam aktivitas sehari-hari. Fakta ini harus direspon dengan efektif oleh pada peneliti, budayawan bahkan masyarakat pemilik bahasa Banjar, sebab kosakata kuno atau arkais ini telah menjadi bagian warisan budaya bahkan jatidiri masyarakat Banjar. Salah satu langkah efesien yang dapat dilakukan ialah dengan melakukan pemertahanan dan pelestarian bahasa daerah yang diwujudkan dengan pendokumentasian, penelitian atau pengkajian secara komperehensif pada kosakata yang dianggap rentan punah. 


\section{METODE}

\section{Lokasi Pengabdian}

Kantor RRI Banjarmasin Jalan Jenderal A.Yani Km 3,5 \& Karang Mekar Kecamatan Banjarmasin Timur Kota Banjarmasin

\section{Ruang Lingkup Pengabdian}

Kegiatan pengabdian kepada masyarakat ini dilaksanakan untuk memberikan pengenalan kosa kata arkais bahasa Banjar melalui siaran RRI Pro 4 Banjarmasin kepada masyarakat Banjar. Kegiatan ini disampaikan dengan metode diskusi dan tanya jawab dengan pendengar RRI Pro 4 Banjarmasin. Peserta kegiatan ini adalah pendengar acara Pandiran Baisukan di saluran RRI Pro 4 Banjarmasin.

\section{Kelompok Sasaran} Banjarmasin.

Kegiatan ini difokuskan bagi pendengar acara Pandiran Baisukan di saluran RRI Pro 4

\section{HASIL DAN PEMBAHASAN}

Beberapa tahap yang dilakukan pada pelaksanaan kegiatan pengabdian ini antara lain :

Tabel Tahapan Kegiatan Pengabdian kepada Masyarakat

\begin{tabular}{cccl}
\hline No. & Pertemuan & \multicolumn{1}{c}{ Waktu } & \multicolumn{1}{c}{ Materi } \\
\hline 1. & 1 & Senin, 09.00-10.00 WITA & $\begin{array}{l}\text { Latar belakang adanya bahasa Banjar } \\
\text { arkais }\end{array}$ \\
\hline 2. & 2 & Senin, 09.00-10.00 WITA & $\begin{array}{l}\text { Pengertian dan contoh bahasa Banjar } \\
\text { arkais }\end{array}$ \\
\hline 3. & 3 & Senin, 09.00-10.00 WITA & $\begin{array}{l}\text { Medan makna } b a \text { 'ah 1 melalui puisi } \\
\text { Y.S Agus Suseno }\end{array}$ \\
\hline 4. & 4 & Senin, 09.00-10.00 WITA & $\begin{array}{l}\text { Medan makna } b a \text { 'ah }^{\prime} \text { melalui puisi } \\
\text { Rezky Atmajaya }\end{array}$ \\
\hline 5. & 5 & Senin, 09.00-10.00 WITA & $\begin{array}{l}\text { Medan makna ekonomi 1 melalui puisi } \\
\text { Y.S Agus Suseno }\end{array}$ \\
\hline 6. & 6 & Senin, 09.00-10.00 WITA & $\begin{array}{l}\text { Medan makna ekonomi 2 melalui puisi } \\
\text { Rezky Atmajaya }\end{array}$ \\
\hline 7. & 7 & Senin, 09.00-10.00 WITA & $\begin{array}{l}\text { Strategi pemertahanan kosa kata arkais } \\
\text { Bahasa Banjar }\end{array}$ \\
\hline
\end{tabular}

Berdasarkan pengamatan yang telah dilakukan setelah kegiatan pengabdian kepada masyarakat dengan tema pengenalan kosa kata arkais Banjar berlokasi di Kantor RRI Banjarmasin Jalan Jenderal A.Yani Km 3,5 \& Karang Mekar Kecamatan Banjarmasin Timur Kota Banjarmasin. Indikator yang dapat dicapai dari pengabdian ini dilihat melalui tanggapan dan antusias pendengar radio pada saluran RRI Pro 4 Banjarmasin. Respon yang didapat dari pendengar juga baik yang dibuktikan dengan beberapa komunikasi interaktif yang terjalin melalui sambungan telepon secara langsung kepada pendengar. 

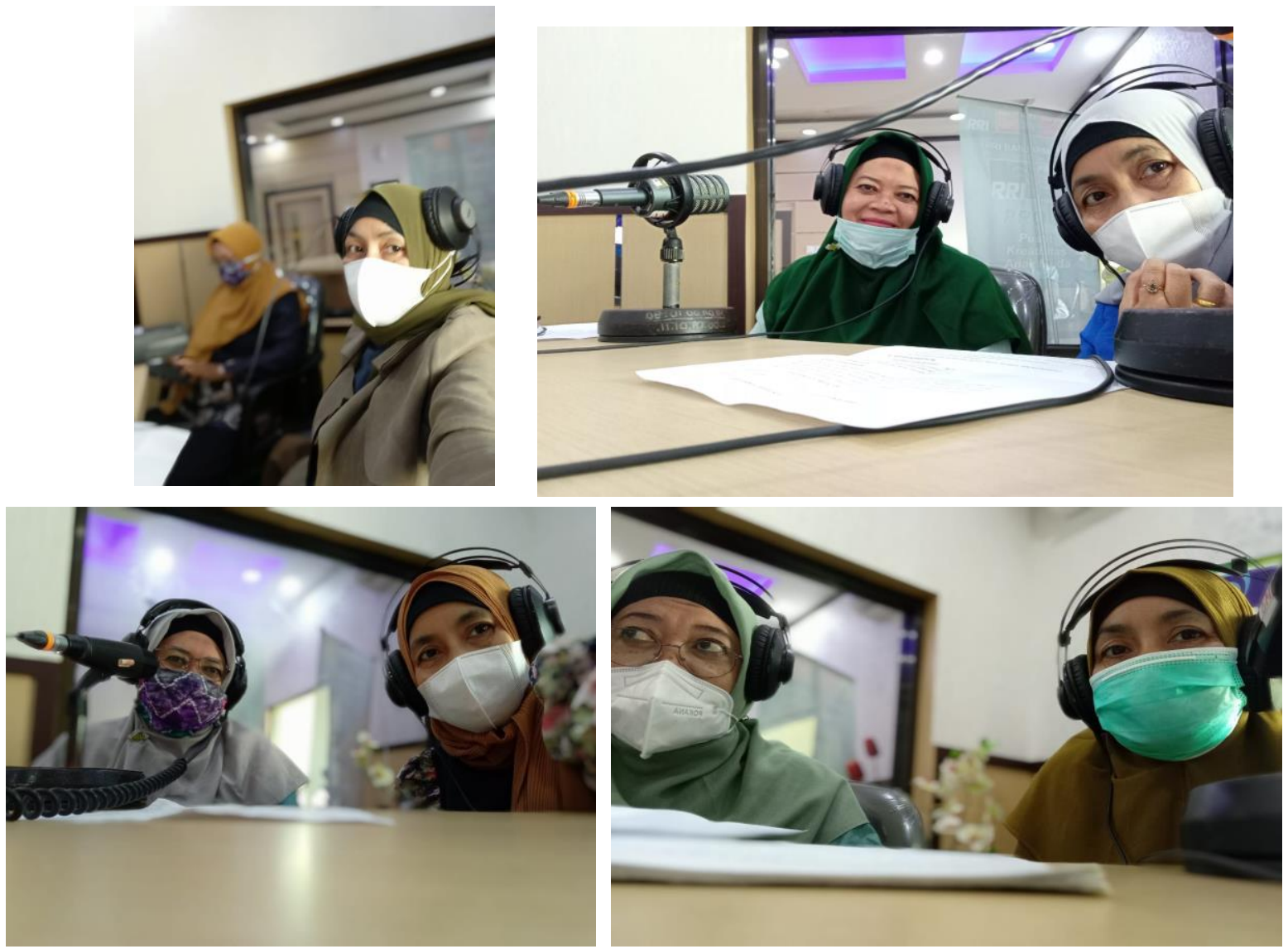

Gambar 1. Pelaksanaan Kegiatan Pengabdian kepada Masyarakat

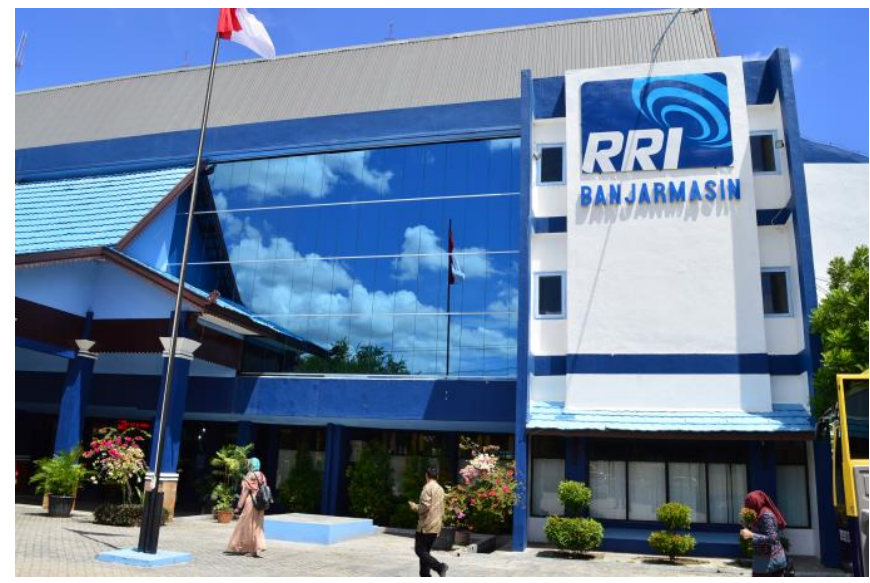

Gambar 2. Lokasi Pelaksanaan Kegiatan Pengabdian kepada Masyarakat

\section{SIMPULAN}

Kegiatan pengabdian kepada masyarakat ini dengan tema pengenalan Bahasa Banjar arkais yang berhubungan dengan medan makna $b a^{\prime} a h$ (banjir) dan ekonomi bertujuan agar masyarakat banjar sebagai pemilik dan pengguna bahasa Banjar mengetahui mengenai bahasa Banjar yang hampir punah karena tidak digunakan lagi dalam kehidupan sehari-hari. Sebelum diadakannya pengenalan 
kosa kata arkais ini, masyarakat Banjar masih kurang menyadari akan adanya kosa kata bahasa Banjar yang mulai hilang, karena dipengaruhi oleh perkembangan budaya dan teknologi.

\section{UCAPAN TERIMAKASIH}

Ucapam terima kasih kepada Kepala RRI Banjarmasin yang telah memfasilitasi kegiatan pengabdian ini dan seluruh pendengar setia PRO 4 RRI Banjarmasin saluran Ensiklopedi dan Kebudayaan Banjar.

\section{DAFTAR PUSTAKA}

Afria, Rengki. 2017. Inventarisasi Kosakata Arkais sebagai Upaya Penyelamatan dan Perlindungan Bahasa Melayu Kouno di Provinsi Jambi. Jurnal Titian. Vol. 1, No. 2, Hal: 254 - 265

Chaer, Abdul dan Agustina Leony. 2004. Sosiolinguistik : Perkenalan Awal. Jakarta: Rineka Cipta . Chaer, Abdul. 2009. Pengantar Semantik Bahasa Indonesia. Jakarta: Rineka Cipta.

Fika, Rahma Aulia. 2018. Pergeseran Makna : Analisis Peyorasi dan Ameliorasi dalam Konteks Kalimat. Jurnal Hasta Wiyata. Vol. 1, No, 2. Hal : 1-11.

Ideham, M. Suriansyah, dkk. 2020. Urang Banjar \& Kebudayaannya. Yogyakarta: Penerbit Ombak. Kridalaksana, Harimurti. 2008. Kamus Linguistik. Jakarta: PT Gramedia Pustaka Utama.

Rexqie M.A. Atmanegara. 2021. Paman Janaki Kamanakan Maristaan. https://asyikasyik.com/paman-janaki-kamanakan-maristaan/ . Januari 2021.

Sempana, Rio, dkk. 2017. Analisis Perubahan Makna pada Bahasa yang Digunakan oleh Komentator Sepak Bola Piala Presiden 2017 Kajian Semantik. Jurnal Widyabastra. Vol. 5, No 2. Desember 2017.

Wakidah, Anisa, dkk. 2019. Pergeseran Makna Sumpah dalam Bahasa Indonesia. Jurnal Bahasa, Sastra dan Pengajarannya. Vol. 3, No. 2. Hal: 179-189.

Suseno. $\quad$ Y.S. $\quad$ Agus. 2021. Puisi: Urang Banua. https://www.facebook.com/100003285597383/posts/3831682816951200/?app=fbl . Januari 2021 